\title{
Gene expression profiling for the diagnosis of multiple primary malignant tumors
}

\author{
Yu Zheng ${ }^{1 \dagger}$, Yifeng Sun ${ }^{2 \dagger}$, Yue Kuai ${ }^{1}$, Guoxiang Fu ${ }^{3}$, Huimin $\mathrm{An}^{3}$, Jinyun Chen ${ }^{4}$, Jinying Chen ${ }^{2}$, Jiajun Zhu ${ }^{2}$, \\ Yixin Wo ${ }^{2}$, Yiwang $\mathrm{Wu}^{2}$, Kaibin Song ${ }^{2}$, Qinghua $\mathrm{Xu}^{2,5^{*}} \mathbb{D}, \mathrm{Di} \mathrm{Wu}^{5}$, Deshuang Huang ${ }^{5}$, Qifeng Wang ${ }^{6,7^{*}}$ \\ and Hongming $\operatorname{Pan}^{1,8^{*}}$
}

\begin{abstract}
Background: The incidence of multiple primary malignant tumors (MPMTs) is rising due to the development of screening technologies, significant treatment advances and increased aging of the population. For patients with a prior cancer history, identifying the tumor origin of the second malignant lesion has important prognostic and therapeutic implications and still represents a difficult problem in clinical practice.

Methods: In this study, we evaluated the performance of a 90-gene expression assay and explored its potential diagnostic utility for MPMTs across a broad spectrum of tumor types. Thirty-five MPMT patients from Sir Run Run Shaw Hospital, College of Medicine, Zhejiang University and Fudan University Shanghai Cancer Center were enrolled; 73 MPMT specimens met all quality control criteria and were analyzed by the 90-gene expression assay.

Results: For each clinical specimen, the tumor type predicted by the 90-gene expression assay was compared with its pathological diagnosis, with an overall accuracy of $93.2 \%$ ( 68 of $73,95 \%$ confidence interval $0.84-0.97$ ). For histopathological subgroup analysis, the 90-gene expression assay achieved an overall accuracy of $95.0 \%$ (38 of 40; $95 \%$ Cl 0.82-0.99) for well-moderately differentiated tumors and $92.0 \%$ ( 23 of $25 ; 95 \% \mathrm{Cl} 0.82-0.99$ ) for poorly or undifferentiated tumors, with no statistically significant difference ( $p$-value $>0.5$ ). For squamous cell carcinoma specimens, the overall accuracy of gene expression assay also reached $87.5 \%$ (7 of 8; 95\% Cl $0.47-0.99$ ) for identifying the tumor origins.
\end{abstract}

Conclusions: The 90-gene expression assay provides flexibility and accuracy in identifying the tumor origin of MPMTs. Future incorporation of the 90-gene expression assay in pathological diagnosis will assist oncologists in applying precise treatments, leading to improved care and outcomes for MPMT patients.

Keywords: Multiple primary malignant tumors, Tissue of origin, Gene expression profiling, 90-gene expression assay, qRT-PCR

\footnotetext{
*Correspondence: qinghua.xu@cancerhelp.cn;

Wangwangqifeng19821982@126.com; panhongming@zju.edu.cn

${ }^{\dagger}$ Yu Zheng and Yifeng Sun contributed equally to this study

${ }^{1}$ Department of Medical Oncology, Sir Run Run Shaw Hospital, College

of Medicine, Zhejiang University, East Qinchun Road 3, Hangzhou 310016,

Zhejiang, China

${ }^{2}$ Canhelp Genomics Research Center, Xinyan Road 22, Hangzhou 311100 ,

Zhejiang, China

${ }^{6}$ Department of Pathology, Fudan University Shanghai Cancer Center, Dong'An Road 270, Shanghai 200032, China

Full list of author information is available at the end of the article
}

\section{Introduction}

Multiple primary malignant tumors (MPMTs) are defined as two or more histologically distinct malignancies in one individual. With the development of screening technologies as well as significant treatment advances, early detection and precise treatment have led to a dramatic increase in the population of cancer survivors. In addition to this increase in the population of cancer survivors, the incidence of MPMTs is rising due to increased aging of the population [1]. Worldwide, a meta-analysis

(c) The Author(s) 2021. This article is licensed under a Creative Commons Attribution 4.0 International License, which permits use, sharing, adaptation, distribution and reproduction in any medium or format, as long as you give appropriate credit to the original author(s) and the source, provide a link to the Creative Commons licence, and indicate if changes were made. The images or other third party material in this article are included in the article's Creative Commons licence, unless indicated otherwise in a credit line to the material. If material is not included in the article's Creative Commons licence and your intended use is not permitted by statutory regulation or exceeds the permitted use, you will need to obtain permission directly from the copyright holder. To view a copy of this licence, visit http://creativeco mmons.org/licenses/by/4.0/. The Creative Commons Public Domain Dedication waiver (http://creativecommons.org/publicdomain/ zero/1.0/) applies to the data made available in this article, unless otherwise stated in a credit line to the data. 
of 12 studies revealed that the frequency of MPMTs in a cancer population varies between 2.4 and $8 \%$ and is up to $17 \%$ within 20 years of follow-up [2]. In China, two epidemiological studies reported that 0.99 to $1.09 \%$ of cancer patients could develop a second primary malignancy [3, 4]. The risk of developing a second primary tumor varies across first tumor type; bladder cancer is most common as the first primary tumor, and lung cancer is the most common second primary tumor [5]. Certain patient populations, including male patients and patients with a history of smoking or alcoholism, are also at higher risk of developing MPMTs $[2,6]$.

When a patient with a prior cancer history has a second malignant lesion, identifying the tumor origin of the new lesion has important prognostic and therapeutic implications and still represents a difficult problem in clinical practice. If the second lesion is a primary cancer, it could be cured by radical operation supplemented by chemotherapy and/or radiotherapy, which is similar to the treatment of a single primary cancer. In contrast, recurrent or metastatic tumors indicate that the primary tumor has progressed to advanced stages. Palliative treatment is the first choice for recurrence or metastasis of the primary tumor. In the clinic, histopathologic analysis can help characterize the tumor origin in most cases. However, tumor heterogeneity and interobserver variation between pathologists can cause confusion, especially when metastatic foci are poorly differentiated or undifferentiated [7].

In recent years, gene expression profiling has been widely studied and has become a powerful tool in distinguishing the origin of tumors. Previous studies have suggested the clinical utility of gene expression profiling in distinguishing synchronous primary malignancies of the ovary and endometrium or metastatic spread from either the ovary or the endometrium, as well as in distinguishing between second primary lung cancer and lung metastasis from head and neck tumors [8, 9]. Nevertheless, few data support the broad application of gene expression profiling for MPMTs.

Recently, Ye et al. established a pan-cancer transcriptome database comprising 5434 specimens representing 21 tumor types (as shown in Additional file 1: Table S1), and adopted the SVM-RFE algorithm (Support Vector Machine Recursive Feature Elimination) to select the Top-10 most predictive genes for each of the 21 tumor types [10]. After removing redundant genes, a list of 90 genes specific to 21 tumor types was identified. The details of 90-gene list were provided in Additional file 2: Table S2. For instance, gene $A C P P$ was significantly overexpressed in prostate cancer, while gene GATA3 was shown to be highly expressed in breast cancer, and gene $S L C 3 A 1$ was significantly over-expressed in kidney cancer
(Additional file 3: Figure S1). Gene Ontology and KEGG pathway analysis reveal that a diverse group of gene families is represented in the 90-gene list [10]. The most significantly enriched gene categories are those involved in specific biological processes, including tyrosine metabolism, fat digestion and absorption, cytokine-cytokine receptor interaction, extracellular matrix-receptor interaction, and gastric acid secretion. Of interest, but not surprisingly, genes described in oncogenic pathways such as those of bladder cancer, melanoma, and prostate cancer were also significantly over-represented, reflecting their differential involvement in a range of tumor classes. Next, a 90-gene expression assay was established for the classification of 21 common tumor types using quantitative real-time polymerase chain reaction (qRT-PCR) methods with total RNA extracted from formalin-fixed, paraffin-embedded (FFPE) tissue [10]. In a validation study that included 609 clinical samples, the 90-gene expression assay demonstrated an overall accuracy of 90.2\% for primary tumors (292/323) and $87.3 \%$ for metastatic tumors (255/286). In addition, Wang et al. applied the 90-gene expression assay for the differential diagnosis of metastatic triple-negative breast cancer (TNBC) [11]. The gene expression assay correctly classified $97.6 \%$ of TNBC lymph node metastases (41/42) and $96.8 \%$ of distant metastatic tumors $(30 / 31)$. Zheng et al. investigated the 90-gene expression assay for diagnosing the tumor origin of brain tumors [12]. The molecular assay showed $100 \%$ accuracy for discriminating primary brain tumors from brain metastases, and correctly predicted primary sites for $89 \%$ of brain metastases (39/44). More recently, Ning et al. demonstrated the strengths of the 90-gene expression assay in distinguishing multiple primary squamous cell carcinomas in head and neck, esophageal, and lung cancers [13]. In current study, we aim to evaluate the performance of the 90-gene expression assay and explore its potential diagnostic utility for MPMTs. Our results show that this PCR-based gene expression assay might serve as a useful tool for identifying the origin of MPMTs.

\section{Methods and materials \\ Sample selection}

This study was approved by the Institutional Review Board of Sir Run Run Shaw Hospital, College of Medicine, Zhejiang University (Hangzhou, China) and Fudan University Shanghai Cancer Center (Shanghai, China). FFPE tumor samples from 41 patients (84 specimens) archived from July 2013 to July 2020 were used in this study. All samples were excisional biopsies and histopathologically confirmed as MPMTs according to the international diagnostic criteria of Warren and Gate [14]. The tumor that was first diagnosed and associated with 
the cause of the patient's initial visit was defined as the first primary cancer, the second diagnosed tumor was considered the second cancer and so forth. According to the Surveillance Epidemiology and End Results (SEER) definitions, all of the first tumors in MPMT patients diagnosed within 6 months were classified as synchronous MPMTs, and tumors diagnosed after more than 6 months were deemed metachronous MPMTs [2]. Hematoxylin and eosin (H\&E)-stained slides from tumor samples were reviewed by two senior pathologists to evaluate the percentage of tumor cells and necrotic areas. If fewer than $60 \%$ of the tumor cells or greater than $40 \%$ of the necrotic area was present on inspection, regions of interest were circled on the H\&E-stained slides, and the corresponding areas from unstained FFPE tissue sections were then manually macro-dissected for tumor enrichment.

\section{Sample preparation and RNA isolation}

The tumor tissue from five to fifteen 5 - $\mu$ m-thick paraffin sections was scraped and placed into a $1.5 \mathrm{~mL}$ microcentrifuge tube. Total RNA was isolated from FFPE samples using an FFPE Total RNA Isolation Kit (Canhelp Genomics, Hangzhou, China) as described previously [15]. Briefly, FFPE tissue was deparaffinized by sequential washing in xylene at $50{ }^{\circ} \mathrm{C}$ for $3 \mathrm{~min}$ and twice in $100 \%$ ethanol. Proteins were digested with proteinase $\mathrm{K}$ solution at $56^{\circ} \mathrm{C}$ for $15 \mathrm{~min}$ and then for another $15 \mathrm{~min}$ at $80{ }^{\circ} \mathrm{C}$ followed by treatment with DNase. Total RNA was eluted from the spin column with $40 \mu \mathrm{L}$ RNase-free water. The total RNA concentration was assessed by a NanoDrop 2000 Spectrophotometer (Thermo Fisher Scientific, Wilmington, DE, United States) at $260 \mathrm{~nm}$, and the purity of extracted total RNA was determined by the ratio of absorbance at $260 \mathrm{~nm}$ to that at $280 \mathrm{~nm}$ (A260/ A280). qRT-PCR analyses were only performed on RNA samples with A260/A280 ratios between 1.7 and 2.1.

\section{Expression profiling of 90 tumor-specific genes}

The qRT-PCR method was used to measure the gene expression levels of 90 tumor-specific genes corresponding to 21 major tumor types as described previously [11]. For each sample, reverse transcription was performed on isolated total RNA using a High-Capacity cDNA Reverse Transcription Kit with RNase Inhibitor (Applied Biosystems, Foster City, CA, United States). Subsequently, qRTPCR was performed using a 7500 Real-Time PCR system (Applied Biosystems) to measure the expression levels of 90 genes. The PCR cycling conditions were $10 \mathrm{~min}$ at $95^{\circ} \mathrm{C}$ and 40 cycles of $15 \mathrm{~s}$ at $95^{\circ} \mathrm{C}$ and $1 \mathrm{~min}$ at $60^{\circ} \mathrm{C}$.

\section{Data analysis}

Gene expression data analysis was performed using the $\mathrm{R}$ software (version 3.6.0) and packages from the
Bioconductor project (version 3.9) [16-18]. The gene expression pattern for each sample was compared with the indicated 21 tumor types by the 90-gene expression signature. Then, similarity scores for each of the 21 tumor types were calculated, which showed similarities in the gene expression pattern between the sample and the indicated tumor type [19]. The similarity score values ranged from 0 (very low similarity) to 100 (very high similarity), which summed up to 100 across all 21 tumor types. The tumor type with the highest similarity score was considered to indicate the tissue of origin. An example of the result from the 90-gene expression assay is shown in Additional file 4: Figure S2.

For each clinical specimen, its pathological diagnosis was considered as the "gold-standard", and the predicted tumor type by the 90-gene expression assay was compared with its pathological diagnosis. For the entire cohort, the overall accuracy of 90-gene expression assay was defined as the number of matched cases between gene expression assay prediction and pathological diagnosis divided by the total number of estimated cases. More specifically, for a certain cancer type C1, four test statistics were assessed as follows: true positives (TPs; samples belong to $\mathrm{C} 1$, and predicted results were $\mathrm{C} 1$ ), true negatives (TNs; samples belong to other cancer types, and predicted results were not $\mathrm{C} 1$ ), false positives (FPs; samples belong to other cancer types, and predicted results were $\mathrm{C} 1$ ), and false negatives (FNs; samples belong to $\mathrm{C} 1$, and predicted results were not $\mathrm{C} 1$ ). For each tumor type, sensitivity and specificity can be calculated by applying the following formulas:

$$
\begin{aligned}
\text { Sensitivity } & =\mathrm{TP} /(\mathrm{TP}+\mathrm{FN}) \text { and specificity } \\
& =\mathrm{TN} /(\mathrm{TN}+\mathrm{FP}) .
\end{aligned}
$$

\section{Results \\ Patients and samples}

Forty-one patients with a total of 84 specimens were enrolled from Sir Run Run Shaw Hospital, College of Medicine, Zhejiang University and Fudan University Shanghai Cancer Center in this study. As shown in Fig. 1, four specimens were excluded because of insufficient tumor content, and two specimens were excluded due to high content of necrotic tissue in the samples; thus, six corresponding patients were excluded. Thirtyfive MPMTs from 73 specimens met all quality control criteria and were analyzed by the 90-gene expression assay. Based on the invasion site of the tumor, 73 specimens were sorted into 12 types, including tumors in the colorectum, gastroesophagus, lung, ovary, endometrium, breast, liver, kidney, urinary, prostate, head \& neck and thyroid. Table 1 presents the demographics of the 35 


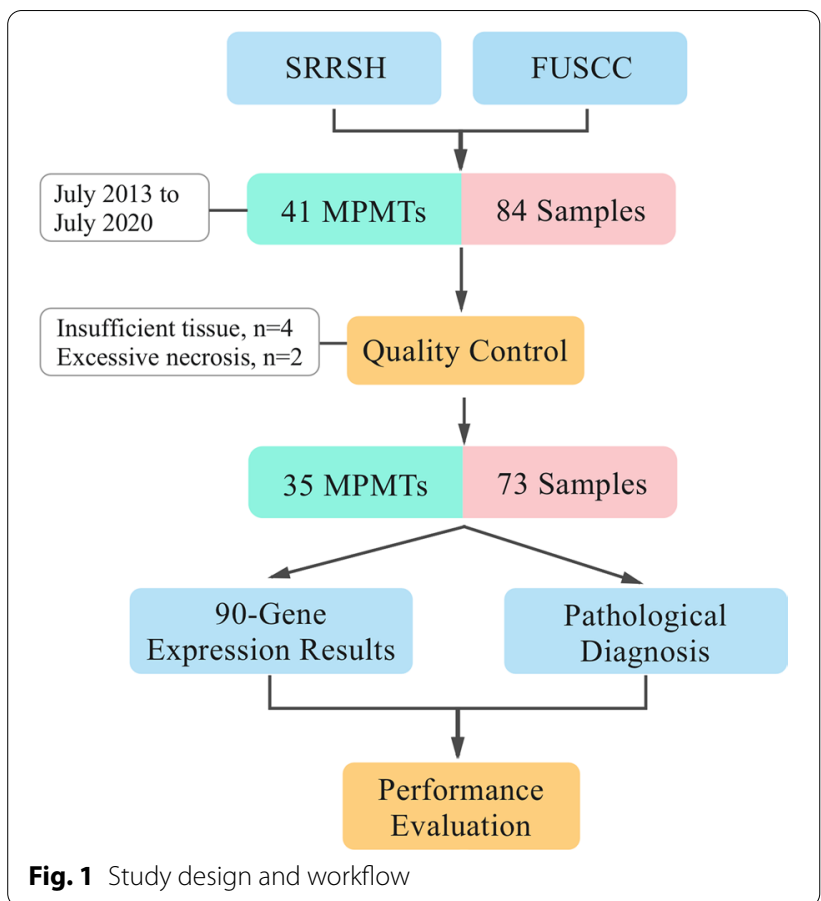

MPMT patients. Among these patients, 30 harbored synchronous MPMTs, and five harbored metachronous MPMTs. Twenty-one patients were male, and fourteen patients were female. The median age at diagnosis was 62.5 (range 33-77) for the first cancer, 63 (range 33-77) for the second cancer and 68 (range 53-70) for the third cancer. The most common invasion sites of the first, second and third tumors were the colorectum, gastroesophagus and colorectum, respectively. Of the 73 specimens, tumors were most frequently located in the colorectum (24.7\%, 18 of 73$)$, gastroesophagus $(16.4 \%, 12$ of 73$)$ and lung (12.3\%, 9 of 73$)$. The distribution of tumor locations is shown in Fig. 2. The most common stages of the first, second and third cancers were II, I and II, respectively. Thirty-two of 35 patients (91.4\%) underwent surgery, and $62.9 \%(22 / 35)$ underwent chemotherapy.

\section{Performance of the 90-gene expression assay in MPMTs}

The overall workflow for the 90-gene expression assay is shown in Fig. 3. The concentrations of total RNA from 73 samples ranged from 3.3 to $255.5 \mathrm{ng} / \mu \mathrm{L}$, with a median of $66.6 \mathrm{ng} / \mu \mathrm{L}$. The median A260/A280 ratio (purity of RNA) was 1.98 (range 1.74-2.04).

With the 90-gene expression assay, 20 specimens were classified as colorectal tumors, 11 as gastroesophageal tumors, 7 as lung tumors, 6 as breast tumors, 6 as ovary tumors, 5 as endometrium tumors, 4 as urinary tumors, 4 as kidney tumors, 3 as liver tumors, 3 as head \& neck tumors, 2 as prostate tumors and 2
Table 1 Patients and tumors characteristics included in this study

\begin{tabular}{|c|c|c|c|}
\hline & First cancer $^{a}$ & $\begin{array}{l}\text { Second } \\
\text { cancer }\end{array}$ & Third cancer \\
\hline \multicolumn{4}{|l|}{ Gender (\%) } \\
\hline Male & & $21(60)$ & \\
\hline Female & & $14(40)$ & \\
\hline \multicolumn{4}{|l|}{ Age at diagnosis } \\
\hline Mean & 62.5 & 63 & 68 \\
\hline Range & $33-77$ & $33-77$ & $53-70$ \\
\hline \multicolumn{4}{|l|}{ Type (\%) } \\
\hline Synchronous & & $30(86)$ & \\
\hline Metachronous & & $5(14)$ & \\
\hline \multicolumn{4}{|l|}{ Stage (\%) } \\
\hline । & $9(26)$ & $18(51)$ & $1(25)$ \\
\hline$\|$ & $17(48)$ & $8(23)$ & $2(50)$ \\
\hline III & $6(17)$ & $6(17)$ & $1(25)$ \\
\hline IV & $3(9)$ & $3(9)$ & $0(0)$ \\
\hline \multicolumn{4}{|l|}{ Invasion site (\%) } \\
\hline Digestive system & $19(54)$ & $13(37)$ & $3(75)$ \\
\hline Reproductive & $5(14)$ & $6(17)$ & $0(0)$ \\
\hline Urinary system & $4(11)$ & $5(14)$ & $1(25)$ \\
\hline Breast & $3(9)$ & $2(6)$ & $0(0)$ \\
\hline Lung & $3(9)$ & $6(17)$ & $0(0)$ \\
\hline Head \& neck & $1(3)$ & $3(9)$ & $0(0)$ \\
\hline \multicolumn{4}{|l|}{ Treatment (\%) } \\
\hline Surgery & & $32(91)$ & \\
\hline Chemotherapy & & $22(63)$ & \\
\hline \multicolumn{4}{|l|}{ Histology (\%) } \\
\hline Well-differentiated & & $40(55)$ & \\
\hline Poorly differentiated & & $25(34)$ & \\
\hline Squamous cell carcinoma & & $8(11)$ & \\
\hline
\end{tabular}

a One triple metachronous MPMT patient lacked the first primary cancer specimen

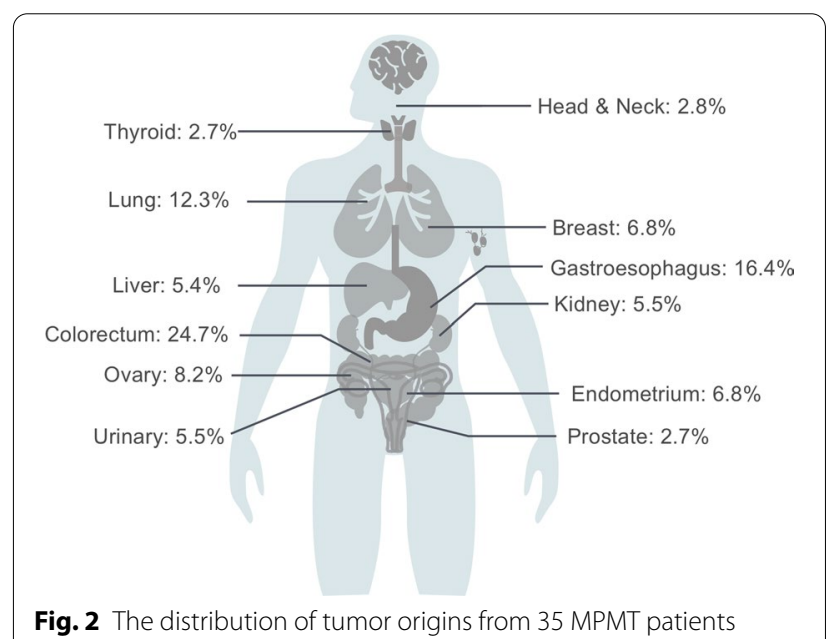



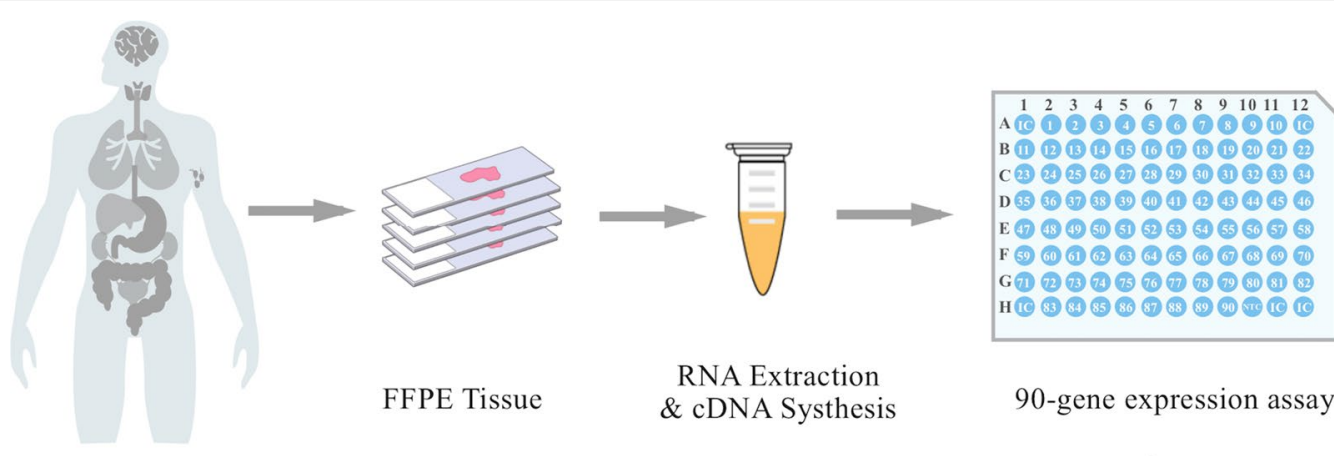

90-gene expression assay

MPMTs
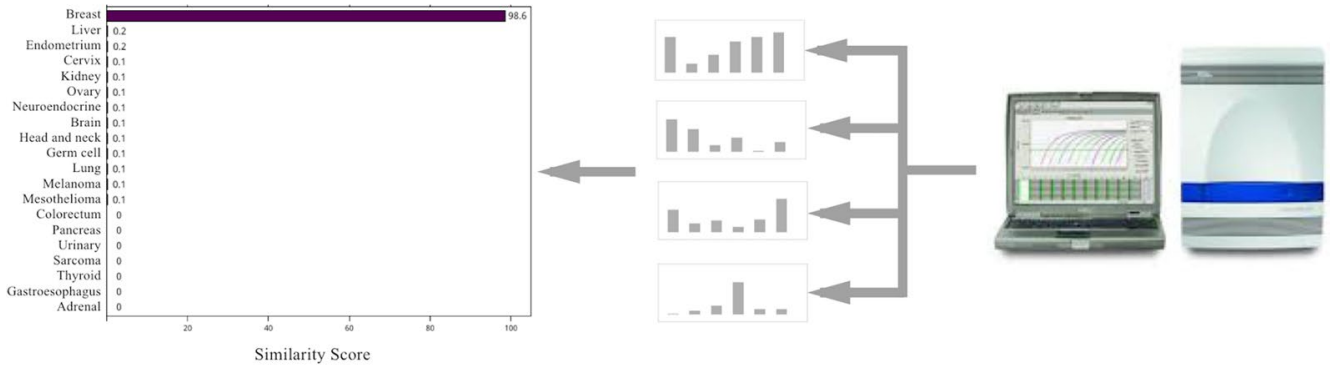

90-gene expression assay result

Data analysis system

qRT-PCR

Fig. 3 Analysis workflow of the 90-gene expression assay. FFPE tissues collected from MPMT patients were used for RNA extraction and qRT-PCR analysis. The gene expression profiling was analyzed by the 90-gene signature with one similarity score for each of the 21 tumor types. The top three predictions were breast (98.6), liver (0.2) and endometrium (0.2); therefore, the most likely site is breast (98.6)

Table 2 Performance of the 90-gene expression assay in MPMTs

\begin{tabular}{lllc}
\hline Tumor type & Number & $\begin{array}{l}\text { \# corrected } \\
\text { predicted }\end{array}$ & Sensitivity (\%) \\
\hline Colorectum & 18 & 18 & 100.0 \\
Gastroesophagus & 12 & 10 & 83.3 \\
Lung & 9 & 7 & 77.8 \\
Ovary & 6 & 6 & 100.0 \\
Endometrium & 5 & 5 & 100.0 \\
Breast & 5 & 5 & 100.0 \\
Liver & 4 & 3 & 75.0 \\
Kidney & 4 & 4 & 100.0 \\
Urinary & 4 & 4 & 100.0 \\
Prostate & 2 & 2 & 100.0 \\
Head \& neck & 2 & 2 & 100.0 \\
Thyroid & 2 & 2 & 100.0 \\
Total accuracy & 73 & 68 & 93.2 \\
\hline
\end{tabular}

as thyroid tumors. For the entire cohort, the 90-gene expression assay showed an overall accuracy of $93.2 \%$ [68 of 73, 95\% confidence interval (CI) 0.84-0.97]. As shown in Table 2, the sensitivity of 90-gene expression assay were $100 \%$ for classifying tumors from the colorectum, ovary, endometrium, breast, kidney, urinary tract, prostate, head \& neck and thyroid. Furthermore, the 90-gene expression assay correctly classified $83.3 \%$ of the gastroesophageal cancer cases, $77.8 \%$ of the lung cancer cases and $75.0 \%$ of the liver cancer cases. As shown in Table 3, 5 out of 73 specimens had discordant molecular classifications compared with the pathological diagnosis, including two lung tumors, two gastroesophageal tumors and one gallbladder tumor.

The performance of 90-gene expression assay stratified by histopathological features was further investigated. Among 73 specimens, 40 (55\%) were well-moderately differentiated tumors, $25(34 \%)$ were poorly or undifferentiated tumors, and 8 (11\%) were squamous cell carcinoma. Regarding to the predictions of 90-gene expression assay, the overall accuracy was $95.0 \%$ (38 of 40; $95 \%$ CI 0.82-0.99) for well-moderately differentiated tumors and $92.0 \%$ ( 23 of 25 ; $95 \%$ CI $0.82-0.99$ ) for poorly or undifferentiated tumors, with no statistically significant difference (p-value $>0.5$ ). In addition, the overall accuracy was $87.5 \%$ (7 of 8; 95\% CI 0.47-0.99) for squamous cell carcinoma. 
Table 3 Investigation of cases with discordant 90-gene expression assay results

\begin{tabular}{|c|c|c|c|c|c|c|c|c|c|}
\hline ID & Gender & Type & First/second/third & Age & $\begin{array}{l}\text { Pathological } \\
\text { diagnosis }\end{array}$ & Grade & $\begin{array}{l}\text { Gene expression } \\
\text { assay results }\end{array}$ & Stage & Treatment \\
\hline 1 & Female & Metachronous & Second cancer & 67 & $\begin{array}{l}\text { Left main bronchus } \\
\text { mucoepidermoid } \\
\text { carcinoma }\end{array}$ & $\begin{array}{l}\text { Highly and mod- } \\
\text { erately differenti- } \\
\text { ated }\end{array}$ & Breast & । & $\begin{array}{l}\text { Surgery \& } \\
\text { chemotherapy }\end{array}$ \\
\hline 2 & Male & Synchronous & Second Cancer & 68 & $\begin{array}{l}\text { Gastric antrum } \\
\text { adenocarcinoma }\end{array}$ & $\begin{array}{l}\text { Poorly differenti- } \\
\text { ated }\end{array}$ & Colorectum & । & $\begin{array}{l}\text { Surgery \& } \\
\text { chemotherapy }\end{array}$ \\
\hline 3 & Female & Synchronous & Primary cancer & 50 & $\begin{array}{l}\text { Gallbladder adeno- } \\
\text { carcinoma }\end{array}$ & $\begin{array}{l}\text { Poorly differenti- } \\
\text { ated }\end{array}$ & Gastroesophagus & $\|$ & Surgery \\
\hline 4 & Female & Synchronous & Second cancer & 72 & $\begin{array}{l}\text { Lung adenocarci- } \\
\text { noma }\end{array}$ & $\begin{array}{l}\text { Highly and mod- } \\
\text { erately differenti- } \\
\text { ated }\end{array}$ & Colorectum & I & $\begin{array}{l}\text { Surgery \& } \\
\text { chemotherapy }\end{array}$ \\
\hline 5 & Male & Metachronous & Primary Cancer & 58 & $\begin{array}{l}\text { Esophageal } \\
\text { squamous cell } \\
\text { carcinoma }\end{array}$ & $\begin{array}{l}\text { Squamous cell } \\
\text { carcinoma }\end{array}$ & Head \& neck & $\|$ & $\begin{array}{l}\text { Surgery \& } \\
\text { chemotherapy }\end{array}$ \\
\hline
\end{tabular}

\section{Specific case}

A 77-year-old man noticed chest tightness, shortness of breath, nausea/vomiting and fever. He underwent endoscopic biopsies in the gastroesophageal region $(29-35 \mathrm{~cm}$ from the incisors) and was diagnosed with squamous cell carcinoma (SCC). In the meantime, a chest computed tomography (CT) scan found a lesion in the left upper lung, and the lung biopsy was diagnosed as SCC. Through comprehensive clinical and pathology examinations, the clinician confirmed that the patient had multiple synchronous primary tumors according to the Warren and Gates criteria [14]. FFPE tumor tissues taken from the esophagus and lung were analyzed by the 90 -gene expression assay, and the predictions showed that the two specimens were gastroesophageal cancer and lung cancer (Fig. 4).

SCC comprises a wide range of tumors originating from diverse anatomical locations that share a common histomorphology and expression of squamous cell differentiation markers, making it difficult to distinguish whether the subsequent SCC is a primary tumor or metastatic lesion. This patient had two simultaneous lesions on the esophagus and lung. Histopathologically, esophageal SCC often metastasizes to the lung. Pathological diagnosis could only confirm the two lesions in the esophagus and lung as SCCs. It was challenge to determine whether the two lesions were synchronous SCCs or represented SCC metastasis based on immunohistochemistry (IHC) and morphology assessment. The clinical outcome of synchronous esophageal and lung SCCs is better than that of metastatic cancer, and the diagnosis of the tumor will directly affect the treatment options. If the new lesion is a second primary tumor, surgical resection supplemented by chemotherapy or radiotherapy has been the preferred therapeutic regimen instead of palliative treatment. Thus, for patients highly suspected of having
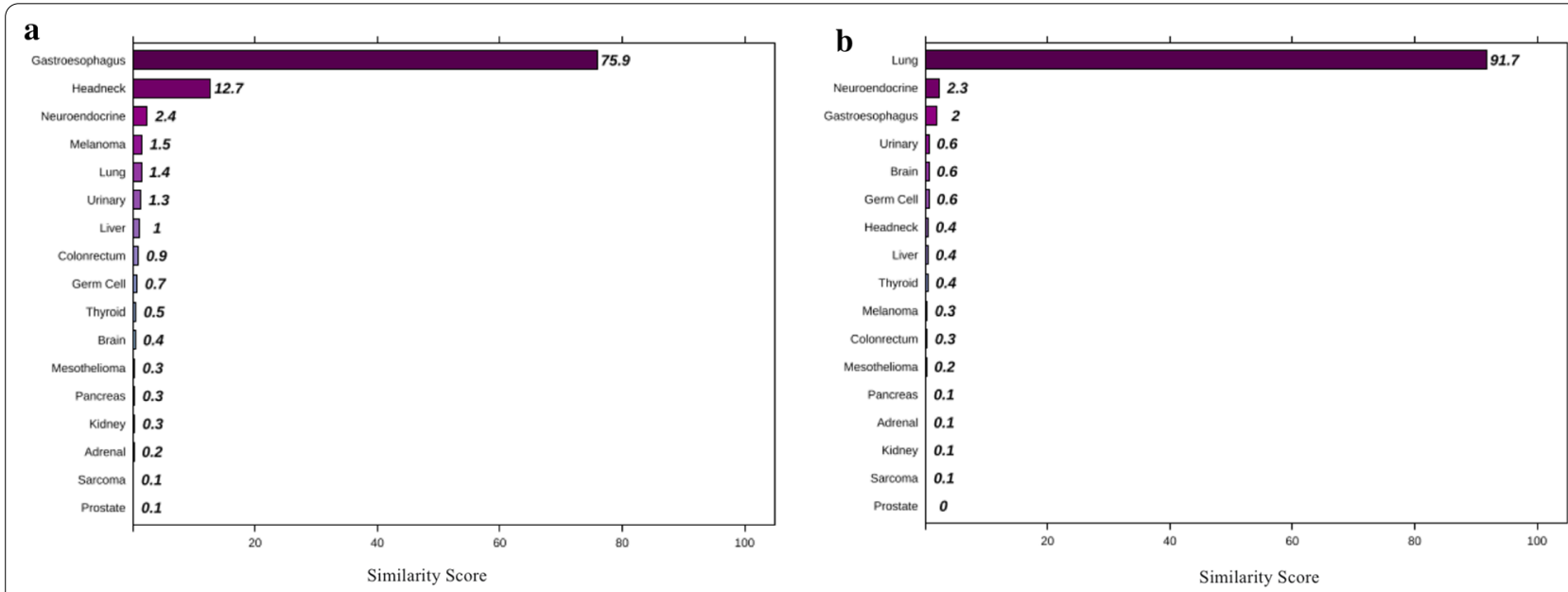

Fig. 4 The 90-gene expression assay results of specific cases. a Esophagus lesion and $\mathbf{b}$ lung lesion 
metastatic cancer, the 90-gene expression assay can be useful to identify the tissue of origin more quickly when imaging and IHC examinations are ineffective, and support the choice of precise treatment.

\section{Discussion}

Currently, with the significant development in tumor screening and diagnostic tools, the detection rate of MPMTs is higher than before. Additionally, the appearance of new treatment methods, including targeted therapy and immunotherapy, has helped cancer patients achieve longer survival. Therefore, the likelihood of cancer survivors having a second malignancy is higher than before because of the longer follow-up times. Lindsay et al. found that the occurrence of cancer survivors developing second cancers rose dramatically from $9 \%$ in 19751979 to $19 \%$ in 2005-2009 [1]. Identifying the tumor origin of the new lesion for patients with cancer history is crucial for selecting the treatment strategy. A second primary cancer could be cured by radical operation supplemented by chemotherapy and/or radiotherapy, which is similar to the treatment of a single primary cancer. In contrast, recurrent or metastatic tumors indicate that the primary tumor has progressed to advanced stages. Palliative treatment is the first choice for recurrence or metastasis of the primary tumor. For people who develop a second primary cancer, $13 \%$ die from their original cancer, and 55\% die from their second primary cancer [5]. Thus, how to accurately diagnose tumors as metastatic or a second primary cancer in a timely manner is becoming increasingly important.

Histopathologic examinations, such as morphological and IHC analyses, are the cornerstone of traditional cancer diagnosis. However, a meta-analysis showed that IHC provides correct tissue identification in $65.6 \%$ of metastatic cancers [20], and recent studies suggest that molecular profiling outperforms classification by IHC, in particular in cases with poorly differentiated tumors [7, 21]. In addition, for patients with multiple SCC lesions, morphological and IHC analyses cannot provide a definite diagnosis of primary site given similar histologic appearances among across several types of SCCs.

Previous studies have demonstrated that gene expression profiling between primary and metastatic tumors shows a high degree of similarity [7, 10]. Efforts have been made to use gene expression profiling to distinguish the second primary tumor from metastatic recurrence. Charles et al. found that gene expression profiling could accurately identify $89 \%$ of metastatic tumors, whereas IHC achieved $83 \%$ agreement. In poorly differentiated or undifferentiated subsets, gene expression profiling correctly distinguished $91 \%$ of cases compared to $71 \%$ using the IHC method [21]. Anita et al. developed a gene expression profiling test to distinguish between synchronous primary malignancies of the ovary and endometrium or metastatic spread from either the ovary or the endometrium and achieved an accuracy of $94.7 \%$ (71/75) [8]. In addition, Anital et al. reported a new approach to determine if a lung nodule was a second primary or a lung metastasis from head \& neck tumors with an overall accuracy of $82.9 \%$ (63/76) [9]. Regardless, few studies have validated the performance of gene expression profiling in MPMTs across a broad spectrum of tumor types.

Here, we describe the investigation of an effective approach for the molecular classification of MPMTs. Similar to findings from previous studies [11, 12], the success rate of the 90-gene expression assay was excellent (87\%), even for samples archived five years prior to analysis, indicating high reliability of the assay with FFPE samples. This may be critical for widespread access and application in clinical practice. The 90-gene expression assay classified 73 MPMT samples into twelve tumor types and reached an overall accuracy of 93.2\% (68/73) when compared with the pathological diagnosis. To the best of our knowledge, this is the first report of a gene expression assay that can be used to classify MPMTs into a wide range of cancer types. Our findings suggest that the 90-gene expression signature may serve as a useful tool for identifying the tumor origin of MPMTs.

Our results represent an encouraging primary step, but this study still has several limitations. First, MPMT patients were enrolled from two hospitals. The number of several tumor types was relatively small to obtain a solid conclusion. In the future, additional multi-center validations should be performed to further evaluate the performance of the 90-gene expression assay. Second, in current study, RNAs extracted from long-term archived FFPE samples are likely degraded, and thus might diminish the distinctness of gene expression pattern cross different cancer types. For routine diagnostic evaluation, fresh tumor or newly prepared FFPE sample reserving high quality RNAs are highly recommended for precise gene expression analysis.

\section{Conclusion}

In conclusion, the results of this study demonstrate the promising performance of the 90-gene expression assay in identifying the tumor origin of MPMTs. In cases which the morphological and IHC work-up cannot clearly confirm the tumor origin, the 90-gene expression assay may serve as a useful tool for identifying primary site of new lesions for cancer patients, especially for SCC patients. Future incorporation of the 90-gene expression assay in tumor origin diagnosis will assist oncologists in applying precise treatments, leading to improved care and outcomes for MPMT patients. 


\section{Supplementary Information}

The online version contains supplementary material available at https://doi. org/10.1186/s12935-021-01748-8.

\section{Additional file 1: Table S1. List of 21 tumor types.}

Additional file 2: Table S2. Details of 90-gene list.

Additional file 3: Figure S1. Examples of genes that differentially expressed across multiple tumor types. Gene ACPP was significantly over-expressed in prostate cancer, gene GATA3 was shown to be highly expressed in breast cancer, and gene SLC3A1 was significantly overexpressed in kidney cancer

Additional file 4: Figure S2. Example of the 90-gene expression assay result. The gene expression pattern was analyzed with the 90-gene signature, with one similarity score for each of the 21 tumor types. The top five tumor origins with highest similarity scores are as follows: Breast (90.3), Cervix (1.7), Ovary (1.6), Germ cell (1.1), and Neuroendocrine (1), thus indicating that the most likely tissue of origin is breast (90.3).

\section{Abbreviations}

CT: Computed tomography; FFPE: Formalin-fixed, paraffin-embedded; H\&E: Hematoxylin and eosin; IHC: Immunohistochemistry; MPMTs: Multiple primary malignant tumors; qRT-PCR: Quantitative real-time polymerase chain reaction; SCC: Squamous cell carcinoma; SEER: Surveillance Epidemiology and End Results; SVM-RFE: Support Vector Machine Recursive Feature Elimination; TNBC: Triple-negative breast cancer.

\section{Acknowledgements}

Not applicable.

\section{Authors' contributions}

YZ, YFS, QHX, QFW and HMP designed the study. YK, QFW and JJZ collected clinical samples and clinical information. YFS, JYC, GXF, HMA, JYC, YXW and YWW performed the experiments. YZ, YFS, KBS, QHX and DW analyzed all data. YZ and YFS wrote the initial manuscript draft. QHX, DSH and HMP critically revised the manuscript and gave valuable insight into the study concept. All authors revised the manuscript. All authors read and approved the final manuscript.

\section{Funding}

This research was supported by Zhejiang Provincial Natural Science Foundation of China under grant No. LSY19H160006 (YZ), the National Natural Science Foundation of China grants 81,401,963 (QFW) and 81,972,728 (QFW), Fudan University Shanghai Cancer Center grant YJYQ201603 (QFW), Shanghai Science and technology development fund grant 19MC1911000 (QFW) and Canhelp Genomics Co., Ltd.

\section{Availability of data and materials \\ Not applicable.}

\section{Ethics approval and consent to participate}

Ethics approval and consent to participate for the study were obtained from the Clinical Research Ethics Committee of Sir Run Run Shaw Hospital, College of Medicine, Zhejiang University and Fudan University Shanghai Cancer Center.

\section{Consent for publication}

Not applicable.

\section{Competing interests}

Authors YF S, JY C, JJ Z, YW W, KB S, YX W and QH X were employed by the company Canhelp Genomics Co., Ltd. The remaining authors declare that the research was conducted in the absence of any commercial or financial relationships that could be construed as a potential conflict of interest.

\section{Author details}

${ }^{1}$ Department of Medical Oncology, Sir Run Run Shaw Hospital, College of Medicine, Zhejiang University, East Qinchun Road 3, Hangzhou 310016, Zhejiang, China. ${ }^{2}$ Canhelp Genomics Research Center, Xinyan Road 22, Hangzhou 311100, Zhejiang, China. ${ }^{3}$ Department of Pathology, Sir Run Run Shaw Hospital, College of Medicine, Zhejiang University, Hangzhou, Zhejiang, China. ${ }^{4}$ Department of General Surgery, Sir Run Run Shaw Hospital, College of Medicine, Zhejiang University, Hangzhou, Zhejiang, China. ${ }^{5}$ Institute of Machine Learning and Systems Biology, College of Electronics and Information Engineering, Tongji University, Shanghai, China. ${ }^{6}$ Department of Pathology, Fudan University Shanghai Cancer Center, Dong'An Road 270, Shanghai 200032, China. ${ }^{7}$ Department of Oncology, Shanghai Medical College, Fudan University, Shanghai, China. ${ }^{8}$ Laboratory of Cancer Biology, Institute of Clinical Science, Sir Run Run Shaw Hospital, College of Medicine, Zhejiang University, Hangzhou, Zhejiang, China.

Received: 24 July 2020 Accepted: 2 January 2021

Published online: 12 January 2021

\section{References}

1. Morton LM, Onel K, Curtis RE, Hungate EA, Armstrong GT. The rising incidence of second cancers: patterns of occurrence and identification of risk factors for children and adults. Am Soc Clin Oncol Educ Book. 2014;34:e57-67.

2. Vogt A, Schmid S, Heinimann K, Frick H, Herrmann C, Cerny T, Omlin A. Multiple primary tumours: challenges and approaches, a review. ESMO Open. 2017;2:e000172.

3. Liu Z, Liu C, Guo W, Li S, Bai O. Clinical analysis of 152 cases of multiple primary malignant tumors in 15,398 patients with malignant tumors. PLOS ONE. 2015;10:e0125754.

4. Zhai C, Cai Y, Lou F, Liu Z, Xie J, Zhou X, Wang Z, Fang Y, Pan H, Han W. Multiple primary malignant tumors - a clinical analysis of 15,321 patients with malignancies at a Single Center in China. J Cancer. 2018;9:2795-801.

5. Donin N, Filson C, Drakaki A, Tan HJ, Castillo A, Kwan L, Litwin M, Chamie K. Risk of second primary malignancies among cancer survivors in the United States, 1992 through 2008. Cancer. 2016;122:3075-86.

6. Irelli A, Sirufo MM, D'Ugo C, Ginaldi L, De Martinis M. Sex and gender influences on cancer immunotherapy response. Biomedicines. 2020;8:232-323.

7. Weiss LM, Chu P, Schroeder BE, Singh V, Zhang Y, Erlander MG, Schnabel CA. Blinded comparator study of immunohistochemical analysis versus a 92-gene cancer classifier in the diagnosis of the primary site in metastatic tumors. J Mol Diagn. 2013;15:263-9.

8. Lal A, Panos R, Marjanovic M, Walker M, Fuentes E, Kapp DS, Henner WD, Buturovic L, Halks-Miller M. A Gene expression profile test for the differential diagnosis of ovarian versus endometrial cancers. Oncotarget. 2012;3:212-23.

9. Lal A, Panos R, Marjanovic M, Walker M, Fuentes E, Kubicek GJ, Henner WD, Buturovic $L$, Halks-Miller M. A gene expression profile test to resolve head \& neck squamous versus lung squamous cancers. Diagn Pathol. 2013:8:1-11.

10. Ye Q, Wang Q, Qi P, Chen J, Ren W, Symposium MXW, 2018. Development and validation of a 90-gene real-time PCR assay for tumor origin identification.

11. Wang Q, Xu M, Sun Y, Chen J, Chen C, Qian C, Chen Y, Cao L, Xu Q, Du X, Yang W. Gene expression profiling for diagnosis of triple-negative breast cancer: a multicenter retrospective cohort study. Front Oncol. 2019;9:115.

12. Zheng $Y$, Ding $Y$, Wang $Q$, Sun $Y$, Teng $X$, Gao Q, Zhong W, Lou X, Xiao C, Chen C, Xu Q, Xu N. 90-gene signature assay for tissue origin diagnosis of brain metastases. J Transl Med. 2019;17:1-9.

13. Qu N, Huang D, Xu Q, Wang J, et CCAB. Gene expression profiling of cells of origin of squamous cell carcinomas in head-and-neck, esophagus, and lung; 2020. http://www.academic.oup.com.

14. Warren S. Multiple primary malignant tumors. A survey of the literature and a statistical study. Am J Cancer. 1932;16:1358-414.

15. Wang Q, Gan H, Chen C, Sun Y, Chen J, Xu M, Weng W, Cao L, Xu Q, Wang $J$. Identification and validation of a 44-gene expression signature for the classification of renal cell carcinomas. J Exp Clin Cancer Res. 2017;36:176. 
16. Ihaka R, Gentleman R. R: a language for data analysis and graphics. arXiv. 1996:5:299-314.

17. Reimers M, Carey VJ. Bioconductor: an open source framework for bioinformatics and computational biology. Meth Enzymol. 2006;411:119-34.

18. Chang C-C, Lin C-J. LIBSVM: a library for support vector machines. ACM Trans Intell Syst Technol TIST. 2011;2:27.

19. Xu Q, Chen J, Ni S, Tan C, Xu M, Dong L, Yuan L, Wang Q, Du X. Pan-cancer transcriptome analysis reveals a gene expression signature for the identification of tumor tissue origin. Mod Pathol. 2016:29:546-56.

20. Anderson GG, Weiss LM. Determining tissue of origin for metastatic cancers: meta-analysis and literature review of immunohistochemistry performance. Appl Immunohistochem Mol Morphol. 2010;18:3-8.
21. Handorf CR, Kulkarni A, Grenert JP, Weiss LM, Rogers WM, Kim OS, Monzon FA, Halks-Miller M, Anderson GG, Walker MG, Pillai R, Henner WD. A multicenter study directly comparing the diagnostic accuracy of gene expression profiling and immunohistochemistry for primary site identification in metastatic tumors. Am J Surg Pathol. 2013;37:1067-75.

\section{Publisher's Note}

Springer Nature remains neutral with regard to jurisdictional claims in published maps and institutional affiliations.
Ready to submit your research? Choose BMC and benefit from:

- fast, convenient online submission

- thorough peer review by experienced researchers in your field

- rapid publication on acceptance

- support for research data, including large and complex data types

- gold Open Access which fosters wider collaboration and increased citations

- maximum visibility for your research: over $100 \mathrm{M}$ website views per year

At BMC, research is always in progress.

Learn more biomedcentral.com/submissions 